\title{
La investigación de operaciones y el contador público
}

\author{
The operations research and the public accountant
}

Claudia García-Pérez ${ }^{a}$

\begin{abstract}
:
Within the operations research, different professionals work together to solve problems of organizations and achieve the established objectives. Such is the case of the public accountant who based on their knowledge and skills, he can perform activities in different areas of a company, such as finance, production, marketing, human resources, among others. Within these areas he can keep the record of accounting and cost analysis, preparation of financial statements, control of taxes, wages and salaries, warehouse management, production control, preparation of investment projects, personnel management, by mention some. He can even give advisory service on the reorganization of companies and do teaching work in educational institutions. This is where the public accountant works with other professionals to solve situations related to administration, planning, logistics and transportation, forecasts and more
\end{abstract}

\section{Keywords:}

Operations research, public accountant, interdisciplinary groups, problems solution.

\section{Resumen:}

Dentro de la investigación de operaciones, distintos profesionales trabajan en conjunto para resolver problemas de las organizaciones y cumplir con los objetivos establecidos. Tal es el caso del contador público quien con base a sus conocimientos y habilidades se puede desempeñar en las diferentes áreas de una empresa, tal es el caso de finanzas, producción, mercadotecnia, recursos humanos, entre otras. Dentro de estas áreas puede llevar el registro de la contabilidad y análisis de costos, elaboración de estados financieros, control de impuestos, de sueldos y salarios, manejo de almacenes, control de la producción, elaboración de proyectos de inversión, administración de personal, por mencionar algunas. Incluso puede dar servicio de asesoramiento sobre la reorganización de las empresas y hacer labor docente en las instituciones educativas. Es aquí en donde el contador público trabaja con otros profesionales para solucionar situaciones relacionadas con la administración, planeación, logística y transporte, pronósticos y otros más.

Palabras Clave:

Investigación de operaciones, contador público, grupos interdisciplinarios, solución de problemas 


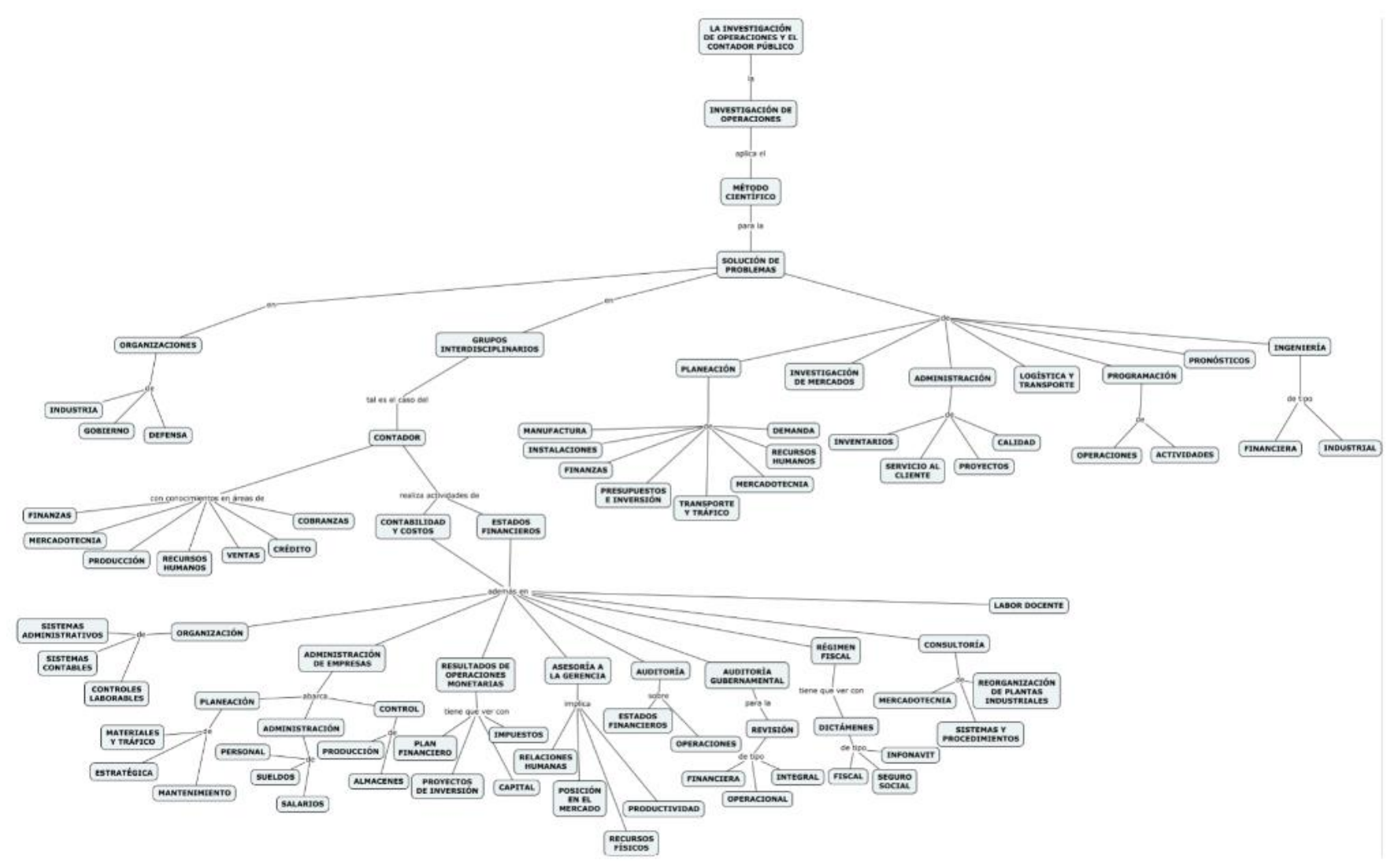

\section{Referencias}

[1] Guerrero, J. C. \& Galindo, J. F. (2014). Contabilidad 1. México: Grupo Editorial Patria.

[2] Montufar, M, A. et al. (2018). Investigación de operaciones. México: Grupo Editorial Patria.

[3] Munguía, L. \& Protti, M. A. (2005). Investigación de operaciones. EUNED. 